\title{
MENINGKATKAN EFISIENSI RUTE PADA PROTOKOL ROUTING AOMDV MENGGUNAKAN METODE PA-SHORT DI JARINGAN MANET
}

\author{
(Improving Route Efficiency on the AOMDV Routing Protocol Using PA-SHORT \\ on the Mobile Ad-Hoc Network)
}

\author{
Yunia Puspita Wulandari, Andy Hidayat Jatmika*, Fitri Bimantoro \\ Program Studi Teknik Informatika, Fakultas Teknik, Universitas Mataram \\ JI. Majapahit 62, Mataram, Lombok NTB, INDONESIA \\ Email: yuniapuspita32@gmail.com, [andy, bimo]@unram.ac.id
}

\begin{abstract}
Mobile Ad-Hoc Network (MANET) is a development of the Ad-Hoc Network, where the nodes of this network have dynamic mobility. There are several types of routing protocols in MANET, one of which is AOMDV. Route discovery on the AOMDV routing protocol is done by calculating the distance based on the number of hops. If the number of hops increased, it may cause a considerable delay and a decrease in throughput. This study compares the performance of the AOMDV routing protocol with the Path Aware-AOMDV (PA-AOMDV) routing protocol. PA-AOMDV routing protocol is obtained through modifications to the performance of the AOMDV protocol with the Path Aware SHORT algorithm. The Path Aware SHORT algorithm is a method to reduce the number of hops. SHORT improves routing optimization by monitoring routes and optimizing these routes that have better paths. The performance of both protocols will be seen based on four parameters, namely throughput, average end-to-end delay, packet delivery ratio, and routing overhead. Result shows that the throughput increased for 50 nodes is $61,84 \%$ and for 100 nodes is $45,2 \%$, average end-to-end delay decreased for 50 nodes is $0,066 \%$ and for 100 nodes $0,12 \%$, packet delivery ratio increased for 50 nodes is $60,87 \%$ and for 100 nodes $82,02 \%$, and routing overhead decreased for 50 nodes is $67,07 \%$ and 100 nodes $45,36 \%$.
\end{abstract}

Keywords: MANET, AOMDV, Path Aware SHORT, PA-AOMDV, Routing Protocol

*Penulis korespondensi

\section{Pendahuluan}

Mobile Ad-Hoc Network (MANET) merupakan jaringan tanpa kabel yang berdiri sendiri, terdiri dari sejumlah node yang mampu bergerak ke segala arah secara bebas. Akibat pergerakan yang bebas tersebut, topologi pada MANET cenderung sering berubah [9]. Karakteristik MANET antara lain wireless, Ad-hocbased, mandiri dan tanpa infrastruktur, multihop routing, dan mobility [1].

Dalam MANET, routing merupakan masalah yang paling mendasar. Masalah dalam hal routing yaitu penemuan jalur yang paling efektif antara node yang berkomunikasi. Seringnya mobilitas node yang bergerak ke segala arah membuat topologi jaringan menjadi tidak menentu [2]. Protokol routing yang digunakan harus mampu menangani segala perubahan topologi yang tidak dapat diprediksi dalam jaringan MANET tersebut.

Protokol routing yang dijadikan objek penelitian ini adalah Ad hoc On-demand Multipath Distance Vector (AOMDV). AOMDV mencari lebih dari satu rute, jika rute yang sedang digunakan mengalami kerusakan, maka AOMDV akan menggunakan rute cadangan yang dimilikinya tanpa harus mencari lagi [3].

Route discovery pada AOMDV dibangun jika komunikasi yang akan diinisiasi oleh node yang tidak memiliki rute, maka protokol routing ini akan mencoba untuk membangun rute [4]. AOMDV menghitung beberapa jalur loop-free dan link disjoint paths [5]. Link disjoint paths cocok untuk AOMDV karena menggunakan perutean multipath untuk mengurangi overhead routing [6]. AOMDV juga menyediakan node tengah untuk menemukan jalur alternatif yang berguna untuk mengurangi frekuensi penemuan rute [7]. AOMDV menyediakan dua layanan yaitu route discovery dan route maintenance.

AOMDV bekerja dengan cara memperhitungkan jarak berdasarkan jumlah hop dalam hal menemukan rute. Apabila pada routing table sudah tidak ada rute cadangan lagi, maka AOMDV akan melakukan pencarian rute kembali dari awal. Drop packet akan terjadi jika adanya pemilihan rute lain yang ada di 
routing table [8]. Perubahan topologi dapat dimanfaatkan dengan mengurangi jumlah hop sebelum terjadi kerusakan rute, sehingga diharapkan mampu meningkatkan throughput dan menurunkan delay. Metode untuk mengurangi jumlah hop adalah algoritma Path Aware SHORT. Tujuan dari algoritma Path Aware SHORT adalah mencoba untuk mempersingkat panjang jalur bila memungkinkan. Rute yang lebih pendek tidak hanya mengurangi latency, tetapi juga meningkatkan throughput [9].

Penelitian ini mengajukan modifikasi pada kerangka protokol routing AOMDV untuk mengoptimalkan rute utama dengan cara mengurangi jumlah hop menggunakan algoritma Path Aware SHORT. Kinerja AOMDV diukur dari nilai parameter yang telah ditentukan yaitu throughput, packet delivery ratio, end-to-end delay, dan routing overhead yang dilakukan pada beberapa skenario berbeda.

\section{Penelitian Terkait}

Penelitian terkait mengenai performansi kinerja protokol routing AODV dan protokol routing AOMDV pernah dilakuakn pada [10]. Hasil simulasi menunjukkan bahwa throughput AOMDV telah meningkat sebesar $27 \%$, network overhead mengalami penurunan sebesar 20\%, dan packet delivery meningkat sebesar $11 \%$ menggunakan protokol routing AOMDV dibandingkan dengan protokol routing AODV. Namun pada AOMDV menunjukkan end-to-end delay yang tinggi dibandingkan dengan protokol routing AODV.

Penelitian terkait optimasi pada protokol routing menggunakan suatu metode yang ditanam pada kerangka protokol pernah dilakukan pada [11]. Penelitian tersebut bertujuan untuk menghitung seberapa lama dua buah node saling berhubungan yang berpengaruh terhadap kehandalan suatu rute. Hasil penelitian tersebut menunjukkan bahwa dengan adanya penambahan suatu metode pada sebuah protokol routing mampu meningkatkan performa jaringan.

Penelitian terkait tentang analisis performansi antara jenis protokol hybrid dengan jenis protokol reaktif pernah dilakukan pada [12]. Penelitian ini melakukan analisis terhadap protokol hybrid yang diwakili oleh MP-OLSR dan protokol reaktif yang diwakili oleh AOMDV. Performansi dari kedua protokol akan dilihat berdasarkan tiga metric, yaitu delay, throughput, dan packet delivery fraction. Berdasarkan hasil analisis dari penelitian ini, protokol MP-OLSR memiliki performansi yang lebih baik dari protokol AOMDV dikarenakan menggunakan algoritma
Transformasi Mojette untuk melakukan pengamanan data sehingga meningkatkan performansi terutama packet delivery fraction.

Penelitian terkait dengan protokol routing AOMDV dimodifikasi dengan penambahan algoritma perhitungan Signal to Noise Ratio (SNR) pernah dilakukan pada [13]. Penambahan algortima tersebut bertujuan agar protokol routing dapat mencari jalur dengan kualitas yang lebih baik. Dari hasil simulasi, diperoleh bahwa kinerja protokol routing AOMDV modifikasi lebih baik daripada AOMDV di semua parameter dan semua skenario perubahan besar paket dan jumlah trafik. Pada skenario perubahan besar paket, throughput mengalami peningkatan sebesar $20 \%$, penurunan NRL sebesar $3 \%$, dan penurunan packet loss sebesar $0,37 \%$. Pada skenario perubahan jumlah trafik, throughput mengalami peningkatan sebesar $12 \%$, penurunan NRL sebesar $0,5 \%$, dan penurunan packet loss sebesar 0,21\%.

Penelitian ini terkait dengan algoritma SHORT (Self-Healing and Optimizing Routing Techniques for Mobile Ad Hoc Networks) [9]. Optimalisasi routing dengan menggunakan metrik yang berbeda seperti panjang lintasan dan pemakaian energi di sepanjang jalur didefinisikan. Saat menggunakan SHORT, semua node tetangga memantau rute dan mencoba mengoptimalkannya bila ada jalur yang lebih baik. Pada penelitian ini, algoritma SHORT diterapkan untuk protokol routing AODV dan DSR. Algortima SHORT meningkatkan optimalisasi routing dengan memonitor jalur routing secara terus menerus dan secara bertahap mengarahkan rute untuk lebih optimal. Hasil simulasi menunjukkan bahwa tingkat pengiriman yang lebih tinggi dan network lifetime yang lebih panjang. Tingkat pengiriman naik sekitar $8 \%$ pada AODV-SHORT dan $6 \%$ pada DSR-SHORT, serta overhead mengalami penurunan sekitar $10 \%$.

Penelitian tentang analisis perbandingan kinerja protokol routing TORA dengan protokol routing TORA yang dimodifikasi dengan algoritma SHORT [14]. Algoritma ini meningkatkan optimalisasi routing secara bertahap memperpendek rute. Hasil simulasi menunjukkan bahwa throughput yang lebih tinggi meningkat hingga 3-50\%, end-to-end delay yang lebih rendah hingga 50\%, delay mengalami penurunan sebesar $50 \%$, penurunan packet loss bervariasi dari $12-$ $57 \%$, perbaikan energi sekitar 43\%, dan life time jaringan yang lebih tinggi.

Penelitian yang dilakukan oleh [15] mengenai efisiensi rute pada protokol routing DSR menggunakan Path Aware SHORT. Pendekatan yang dilakukan untuk pencarian rute pada protokol DSR pada penelitian ini 
yaitu optimasi pencarian rute diantara node yang tidak membebani link, karena jika terjadi kegagalan link maka akan dilakukan route discovery ulang. Perhitungan optimasi rute menggunakan fungsi obyektif digunakan untuk mencapai rute menjadi optimum dengan parameter waktu tempuh yang paling minimal. Untuk mendukung informasi optimasi link - link yang menyusun rute digunakan Algoritma Path Aware SHORT dengan memastikan bahwa link yang akan dilalui dalam kondisi baik. Hasil penelitian menunjukkan ujicoba skenario I nilai optimum AVG untuk 50 node $0.002 \mathrm{~m} / \mathrm{s}$ dan 100 node $0.0051 \mathrm{~m} / \mathrm{s}$. Nilai optimum NRL untuk 50 node 0.026 dan 100 node 0.0136 . Nilai optimum PDR untuk 50 node $78.5801 \%$ dan 100 node 81.7333\%. Sedangkan hasil ujcoba skenario II nilai optimum AVG untuk 50 node $0.0004 \mathrm{~m} / \mathrm{s}$ dan 100 node $0.0007 \mathrm{~m} / \mathrm{s}$. Nilai optimum NRL untuk 50 node 0.0112 dan 100 node 0.0058 . Nilai optimum PDR untuk 50 node $85.6523 \%$. dan 100 node 98.9327\%.

\section{MeKanisme PA-SHORT}

Rute yang telah ditemukan dari node sumber $A$ ke node tujuan I memiliki jalur A-B-C-D-E-F-G-H-I seperti yang ditunjukkan pada Gambar 1 (a). Jalur awal ini ditentukan melalui proses penemuan jalur, di mana jarak antara sumber dan tujuan adalah jarak terpendek menurut jumlah hop. Dibutuhkan 8 hop untuk pengiriman paket saat bergerak dari node $A$ ke node I. Selama perjalan waktu, mobilitas node dapat membuat bentuk jalur menjadi gambar yang ditunjukkan pada Gambar 1 (b). Selama perjalan waktu ini rute yang terbentuk mempertahankan konektivitas. Dalam bentuk baru ini, node J mendekati node $A$ sehingga node $J$ berada dalam transmisi node $A$ dan node $\mathrm{E}$ berada dalam transmisi node J. Pada Gambar 1 (b) node $\mathrm{H}$ berada dalam transmisi node $\mathrm{F}$. Jadi, untuk efisiensi rute, jalur terpendek dari node $A$ ke node I hanya membutuhkan 5 hop seperti yang ditunjukkan pada Gambar 1 (c) [9].

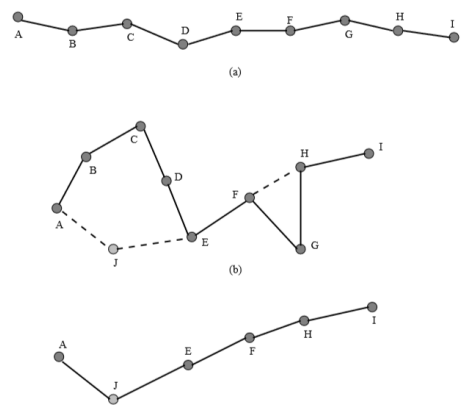

Gambar 1. Perubahan jalur rute

\section{Metode Penelitian}

\subsection{Diagram Alir Penelitian}

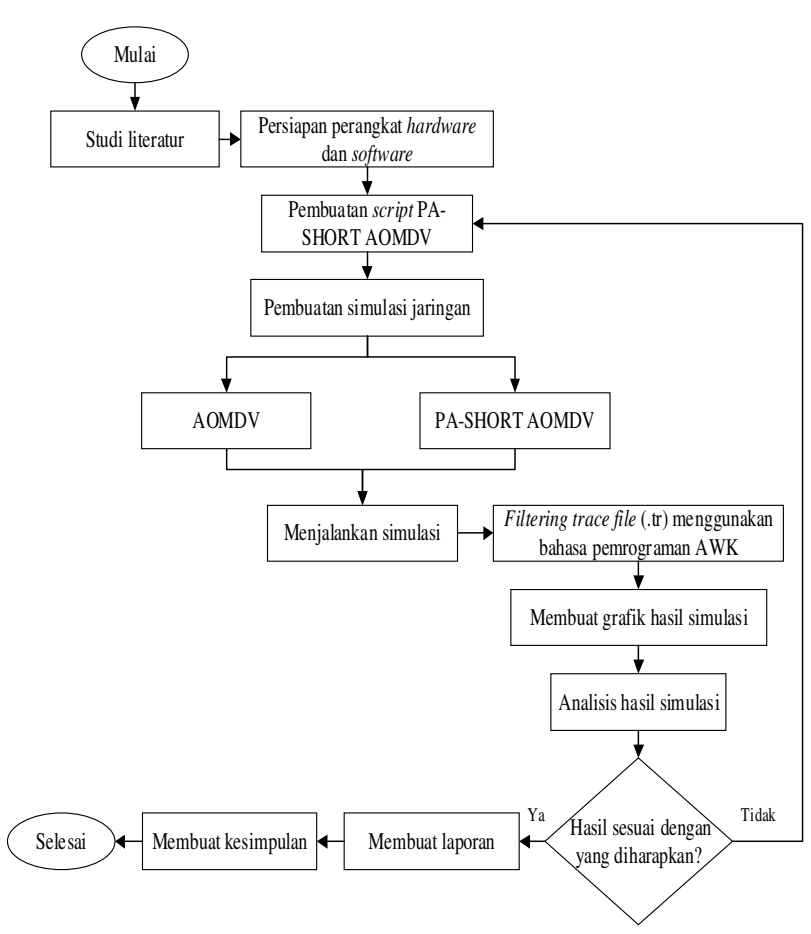

Gambar 2. Diagram alir penelitian.

Gambar 2 merupakan gambaran aliran penelitian yang akan dilakukan. Langkah awal dari penelitian ini adalah melakukan studi pustaka melalui jurnal ilmiah maupun buku dengan memahami berbagai konsep yang terkait dengan penelitian ini. Hardware dan software yang digunakan untuk menunjang penelitian ini adalah laptop, NS-2.35 sebagai network simulator, Microsoft Excel untuk membuat grafik hasil simulasi, dan Linux Ubuntu sebagai sistem operasi. Pembuatan script PA-SHORT AOMDV dilakukan dengan cara memodifikasi protokol routing AOMDV dengan menyisipkan Algoritma PA-SHORT pada protokol AOMDV. Pembuatan simulasi jaringan dilakukan untuk protokol AOMDV tanpa modifikasi dan protokol AOMDV yang telah dimodifikasi dengan Algoritma PASHORT. Setelah simulasi dijalankan, kemudian pengambilan data dari trace file yang nantinya data tersebut akan di-filtering menggunakan bahasa pemrograman AWK untuk mendapatkan nilai throughput, average end to end delay, packet delivery ratio, dan routing overhead. Hasil dari simulasi sistem akan berupa grafik dan data-data yang kemudian akan dianalisis dan dibandingkan performansi dari AOMDV dengan AOMDV yang telah dimodifikasi. 


\subsection{Algoritma Penemuan Rute AOMDV}

Proses menemukan rute pada AOMDV diperlihatkan pada Gambar 3. Node sumber dinotasikan oleh Node $S$, sedangkan node F merupakan node tujuan. Saat node $S$ ingin mengirim paket ke node $\mathrm{F}$, node $\mathrm{S}$ melakukan broadcast pesan berupa paket RREQ ke node terdekatnya yaitu node $A$ dan node $B$. Node $A$ dan node $B$ akan mengecek paket RREQ yang datang tersebut. Karena node $A$ dan node $B$ bukan node tujuan, maka paket RREQ diteruskan lagi secara broadcast oleh node A dan node $B$ ke node terdekatnya. Proses menemukan rute terus berulang sampai paket RREQ diterima oleh node tujuan dalam hal ini adalah node F. Ketika paket RREQ diterima node $\mathrm{F}$, maka node $\mathrm{F}$ akan membalas dengan paket RREP.

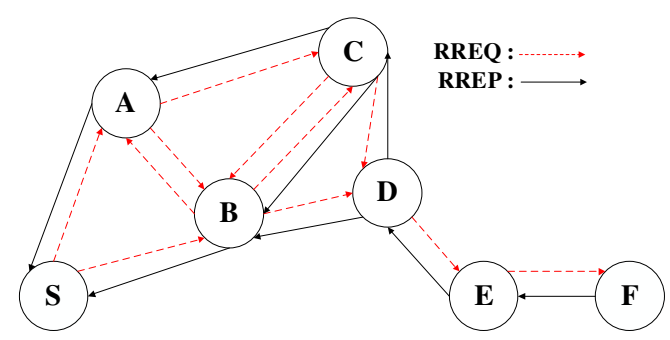

Gambar 3. Proses pencarian rute pada AOMDV

Proses penemuan rute protokol AOMDV dapat dilihat pada Gambar 4.

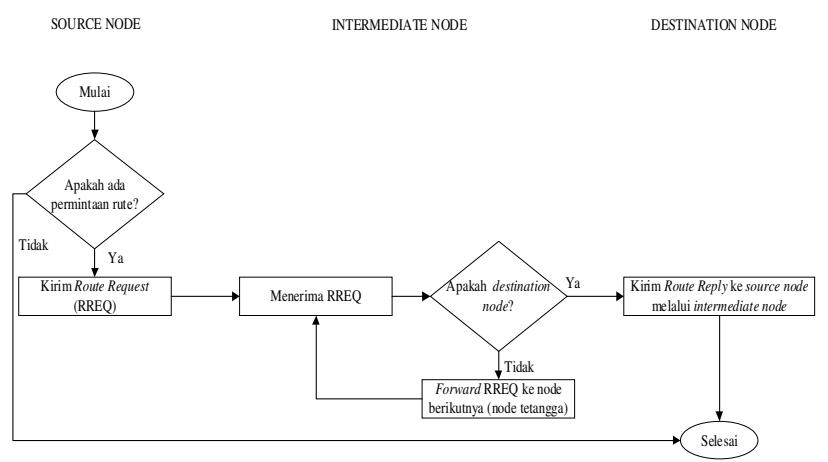

Gambar 4. Flowchart penemuan rute AOMDV

\subsection{Algoritma Path Aware SHORT AOMDV}

Ketika paket dikirim, node akan mengecek apakah paket ditujukan untuk node tersebut atau tidak. Apabila paket tersebut telah sampai node tujuan, maka paket langsung dikirim. Jika bukan node tujuan, paket akan diteruskan melalui rute ke intermediate node dan informasi $\mathrm{HC}$ disimpan ( $\mathrm{HCi}$ ). Ketika paket yang lainnya datang untuk dikirim, paket akan dikirim melalui intermediate node $(\mathrm{HCj})$. $\mathrm{HC}$ adalah banyaknya hop yang dilewati pada rute untuk mengirim paket. Jika $\mathrm{HCi}$ dikurangi dengan $\mathrm{HCj}$ hasilnya lebih besar dari 2, maka rute short-cut ditemukan. Jika tidak, maka rute shortcut tidak ditemukan dan paket diteruskan ke node selanjutnya. Setelah rute short-cut ditemukan, node akan mengirim pesan ke node sebelumnya untuk memperbarui tabel routing, sehingga rute yang digunakan adalah rute short-cut. Pencarian rute dengan PA-SHORT ditunjukkan pada Gambar 5.

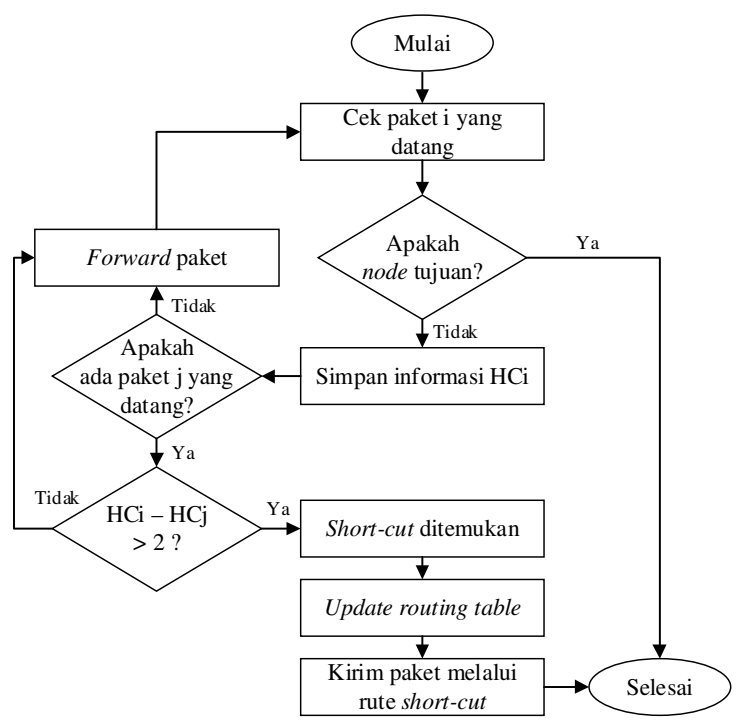

Gambar 5. Flowchart PA-SHORT.

Algoritma Path Aware SHORT mengoptimalkan rute berdasarkan hop terpendek, maka dari itu pada header tiap paket membawa field hop-count (HC). Field hop-count (HC) diinisialisasi ke nol pada node sumber dan bertambah setiap satu dari setiap hop yang dibutuhkan paket. Pada packet header terdapat informasi berupa alamat tujuan (DA), alamat sumber (SA), dan hop-count (HC). Terdapat NA, yaitu alamat tetangga dalam transmisi node yang menyiarkan paket. Format setiap entri adalah $\langle S A, D A, H C, N A\rangle$.

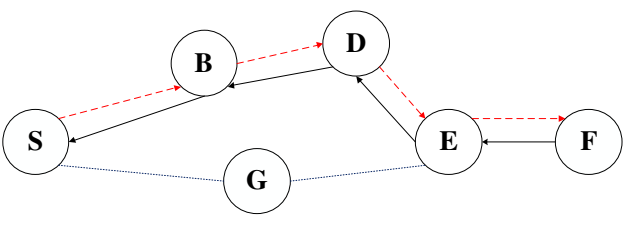

Gambar 6. Contoh perubahan jalur rute.

Contoh pada Gambar 6 akan dianalisis dalam bentuk langkah-langkah, di mana langkah-langkah tersebut menjelaskan proses broadcast pada node. Berikut langkah-langkah tiap node saat perubahan rute : 
a. Node $S$ akan meneruskan paket ke node B. Paket ini diinisialisasi $S$ sebagai (S, F, 0, S). Hopcount awal bernilai 0 . Node $B$ dan node $G$ berada dalam jangkauan node $\mathrm{S}$. Kedua node tersebut menerima broadcast. Node B dan node $G$ bukan node tujuan, sehingga node $B$ dan node $G$ mencatat $(S, F, 0, S)$.

b. Untuk meneruskan paket ke node $D$, node $B$ broadcast paket dengan $\mathrm{HC}=1$. Node $S$ dan node $D$ yang berada dalam jangkauan node $B$. Node D mencatat (S, F, 1, B).

C. Node D broadcast paket ke node E dengan HC $=2$. Node $B$ dan node $E$ yang berada dalam jangkauan node $D$. Node $E$ mencatat $(S, F, 2$, D). Sampai saat ini belum ada rute yang diperbaharui karena belum ada perbedaan $\mathrm{HC}$ yang lebih dari 2. Saat meneruskan paket ke node $F$, node $E$ broadcast dengan $\mathrm{HC}=3$. Node $D, F$, dan $G$ berada dalam jangkauan node $E$. Node F menerima paket langsung karena node F merupakan node tujuan. Node B membandingkan $\mathrm{HC}$ dengan entri yang tersimpan. Perbedaan HC tidak lebih dari 2, sehingga tidak ada yang diperbarui pada node D. Node $F$ dan node $G$ mencatat $(S, F, 3, E)$. Perbedaan $\mathrm{HC}$ pada node $\mathrm{G}$ lebih dari 2 yaitu 3. Jadi, node $G$ mengirim pesan ke node $S$ untuk memperbarui tabel routing sehingga node berikutnya dari node $S$ untuk tujuan $F$ adalah node $G$. Node $G$ memperbarui tabel routing-nya sendiri untuk mengirim paket ke hop berikutnya untuk tujuan node $F$ adalah node E. Rute S-G-E dibuat sebagai jalan pintas untuk rute S-B-D-E sebelumnya. Jadi, rute dari node $S$ ke node $F$ adalah S-G-E-F.

\subsection{Parameter Pengukuran}

Pada Sub Bab ini akan dibahas beberapa parameter yang digunakan untuk menguji kinerja PASHORT AOMDV terhadap AOMDV.

\subsubsection{Throughput}

Throughput adalah paket data yang mengalir per detik pada suatu media transmisi, rumus seperti pada persamaan (1).

$$
\text { Throughput }(\mathrm{Kbps})=\frac{\text { Ukuran data yang dikirim }}{\text { Total waktu pengiriman data }}
$$

\subsubsection{End-to-end delay}

End-to-end delay merupakan waktu yang dibutuhkan suatu paket ketika dikirim oleh node sumber sampai berhasil diterima oleh node tujuan, rumus seperti pada persamaan (2).

$$
\begin{aligned}
& \text { Average delay }(\mathrm{s})=\frac{\text { Total delay }}{\text { Total paket yang diterima }} \\
& \text { Dimana : }
\end{aligned}
$$

Delay = waktu yang diterima - waktu yang dikirim

\subsubsection{Packet Delivery Ratio (PDR)}

PDR merupakan rasio jumlah paket yang diterima dengan total paket yang dikirimkan dalam suatu periode waktu tertentu, rumus seperti pada persamaan (3).

$$
\text { PDR }(\%)=\frac{\text { Paket data yang diterima }}{\text { Paket data yang dikirim }} \times 100 \%
$$

\subsubsection{Routing Overhead}

Routing overhead merupakan paket routing yang ada dalam jaringan dimana berisi informasi node-node yang telah dilewati, rumus seperti pada persamaan (4).

Routing overhead $=\frac{\text { Jumlah paket routing }}{\text { Paket data yang diterima }}$

\subsection{Parameter Simulasi}

Parameter skenario simulasi pada penelitian ini dapat dilihat pada Tabel I.

TABEL I. PARAMETER SKENARIO

\begin{tabular}{|l|l|}
\hline \multicolumn{2}{|c|}{ Parameter Skenario } \\
\hline \multicolumn{1}{|c|}{ Tipe Parameter } & \multicolumn{1}{c|}{ Nilai Parameter } \\
\hline MAC layer & IEEE 802.11 \\
\hline Jumlah node & 50 node, 100 node \\
\hline Network area & $500 \times 500 \mathrm{~m}^{2}, 1000 \times 1000 \mathrm{~m}^{2}$ \\
\hline Waktu simulasi & $600 \mathrm{~s}$ \\
\hline Kecepatan node & $1 \mathrm{~m} / \mathrm{s}, 5 \mathrm{~m} / \mathrm{s}, 10 \mathrm{~m} / \mathrm{s}$ \\
\hline Pause time & $45 \mathrm{~s}, 90 \mathrm{~s}, 180 \mathrm{~s}$ \\
\hline Pergerakan node & Random Waypoint \\
\hline Propagation & TwoRayGround \\
\hline Pola trafik & CBR \\
\hline Channel & Wireless \\
\hline
\end{tabular}

\section{Hasil dan PEMBahasan}

\subsection{Analisis Throughput}

Skenario uji coba pertama adalah mencari ratarata jumlah paket yang sukses diterima per detiknya di sisi penerima.

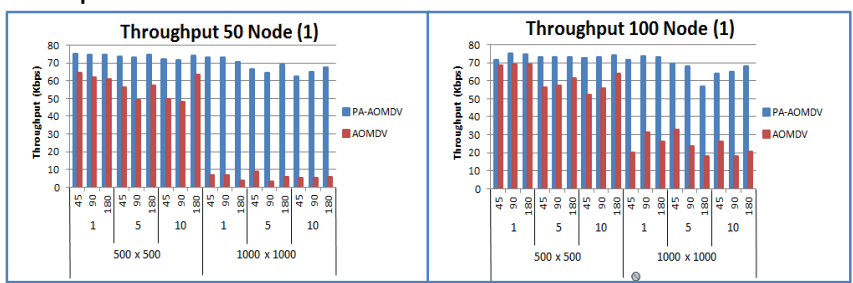

(a)

(b) 


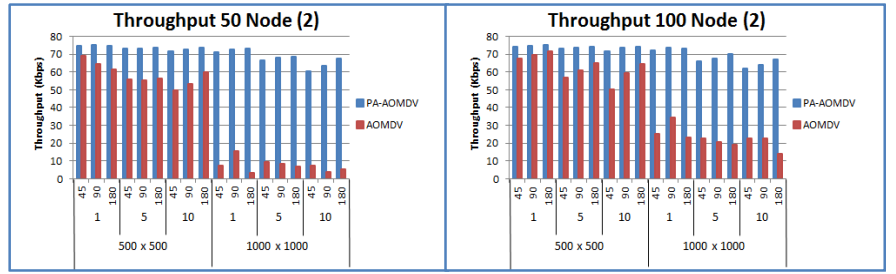

(c)

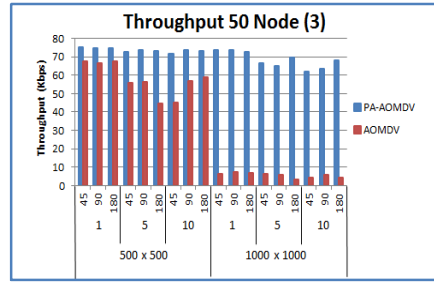

(e) (d)

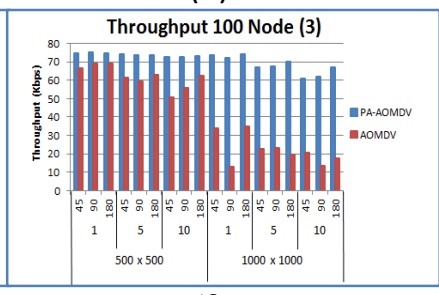

(f)

Gambar 7. Nilai throughput pada 3 percobaan. (a) Node 50 percobaan 1; (b) Node 100 percobaan 1; (c) Node 50 percobaan 2; (d) Node 100 percobaan 2; (c) Node 50 percobaan 3; (d) Node 100 percobaan 3;

Pada Gambar 7 (a) dan Gambar 7 (b) yaitu hasil uji coba 1 , nilai optimum yang didapatkan dari hasil uji coba perbandingan PA-AOMDV dan AOMDV pada 50 node yaitu $74,98 \mathrm{Kbps}$ dan $64,37 \mathrm{Kbps}$. Sedangkan nilai optimum yang didapatkan pada 100 node yaitu PAAOMDV 75,03 Kbps dan AOMDV 69,05 Kbps.

Pada Gambar 7 (c) dan Gambar 7 (d) yaitu hasil uji coba 2, nilai optimum yang didapatkan dari hasil uji coba perbandingan PA-AOMDV dan AOMDV pada 50 node yaitu $74,96 \mathrm{Kbps}$ dan $68,98 \mathrm{Kbps}$. Sedangkan nilai optimum yang didapatkan pada 100 node yaitu PAAOMDV 75,45 Kbps dan AOMDV 71,57 Kbps.

Pada Gambar 7 (e) dan Gambar 7 (f) yaitu hasil uji coba 3, nilai optimum yang didapatkan dari hasil uji coba perbandingan PA-AOMDV dan AOMDV pada 50 node yaitu 75,08 Kbps dan 67,44 Kbps. Sedangkan nilai optimum yang didapatkan pada 100 node yaitu PAAOMDV 75,29 Kbps dan AOMDV 69,30 Kbps.

Rata-rata hasil uji coba pada luas area $500 \times 500$ m2 untuk 50 node pada PA-AOMDV adalah 73,66 Kbps dan 57,63 Kbps pada AOMDV. Sedangkan rata-rata hasil uji coba untuk 100 node pada PA-AOMDV adalah 73,71 Kbps dan 62,16 Kbps pada AOMDV.

Rata-rata hasil uji coba pada luas area $1000 \times 1000$ m2 untuk 50 node pada PA-AOMDV adalah 68,13 Kbps dan 6,29 Kbps pada AOMDV. Sedangkan rata-rata hasil uji coba untuk 100 node pada PA-AOMDV adalah 68,16 Kbps dan 22,96 Kbps pada AOMDV.

\subsection{Analisis End-to-End Delay}

Skenario uji coba kedua adalah mencari nilai selang waktu yang dibutuhkan oleh paket ketika melewati jaringan yaitu dari node sumber sampai sukses diterima oleh node tujuan.

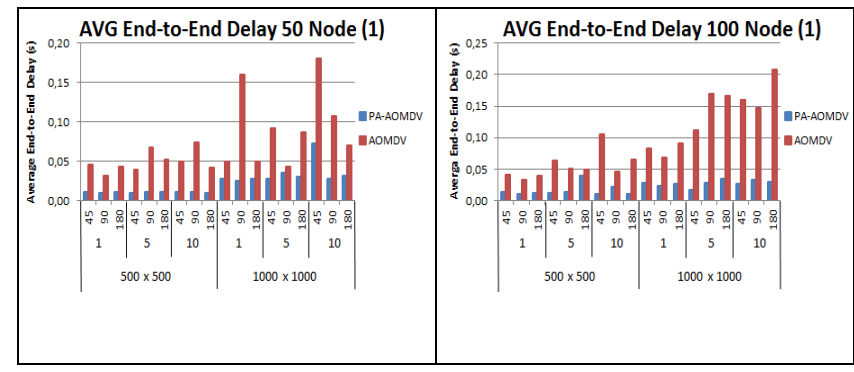

(a)

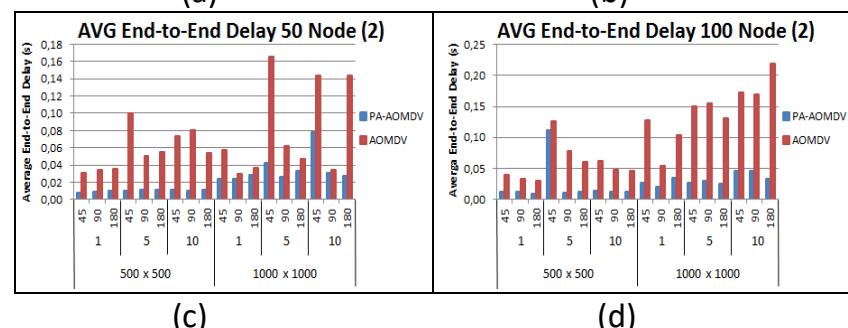

(c)

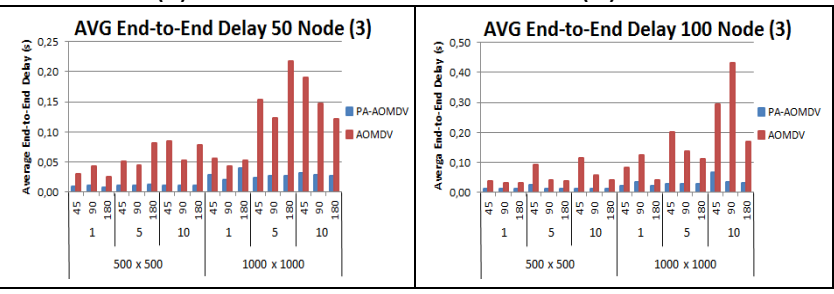

(e)

Gambar 8. Perbandingan nilai average end-to-end delay pada 3 percobaan. (a) Node 50 percobaan 1; (b) Node 100 percobaan 1; (c) Node 50 percobaan 2; (d) Node 100 percobaan 2; (c) Node 50 percobaan 3; (d) Node 100 percobaan 3;

Pada Gambar 8 (a) dan Gambar 8 (b) yaitu hasil uji coba 1 , nilai optimum yang didapatkan dari hasil uji coba perbandingan PA-AOMDV dan AOMDV pada 50 node yaitu $0,00948 \mathrm{~s}$ dan $0,03133 \mathrm{~s}$. Sedangkan nilai optimum yang didapatkan pada 100 node yaitu PAAOMDV 0,01067 s dan AOMDV 0,03389 s. Pada Gambar 8 (c) dan Gambar 8 (d) yaitu hasil uji coba 2, nilai optimum yang didapatkan dari hasil uji coba perbandingan PA-AOMDV dan AOMDV pada 50 node yaitu 0,00814 s dan 0,03049 s. Sedangkan nilai optimum yang didapatkan pada 100 node yaitu PAAOMDV 0,00913 s dan AOMDV 0,03076 s. Pada Gambar 8 (e) dan Gambar 8 (f) yaitu hasil uji coba 3, nilai optimum yang didapatkan dari hasil uji coba perbandingan PA-AOMDV dan AOMDV pada 50 node yaitu $0,00815 \mathrm{~s}$ dan $0,02594 \mathrm{~s}$. Sedangkan nilai 
optimum yang didapatkan pada 100 node yaitu PAAOMDV 0,01041 s dan AOMDV 0,03008 s. Rata-rata hasil uji coba pada luas area $500 \times 500 \mathrm{~m}^{2}$ untuk 50 node pada PA-AOMDV adalah 0,01047 s dan 0,05373 s pada AOMDV. Sedangkan rata-rata hasil uji coba untuk 100 node pada PA-AOMDV adalah 0,01742 s dan 0,05549 s pada AOMDV. Rata-rata hasil uji coba pada luas area $1000 \times 1000 \mathrm{~m}^{2}$ untuk 50 node pada PAAOMDV adalah 0,03243 s dan 0,09849 s pada AOMDV. Sedangkan rata-rata hasil uji coba untuk 100 node pada PA-AOMDV adalah 0,03061 s dan 0,15088 s pada AOMDV.

\subsection{Analisis Packet Delivery Ratio (PDR)}

Skenario uji coba ketiga adalah mencari nilai perbandingan atau rasio antara paket data yang terkirim dengan jumlah paket data yang dikirimkan oleh node sumber (paket data yang di-generate node sumber).
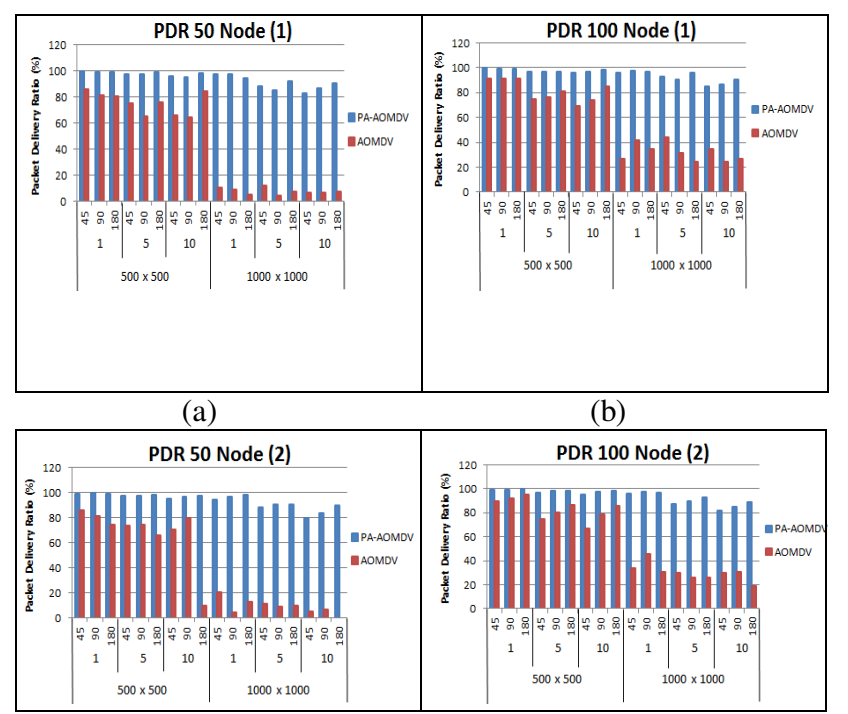

$$
\text { (c) }
$$

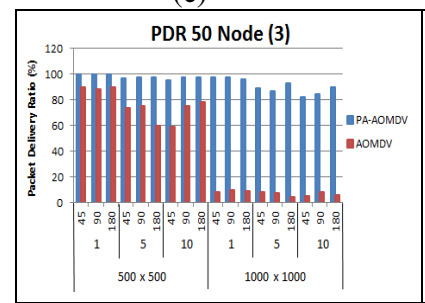

(e) (d)

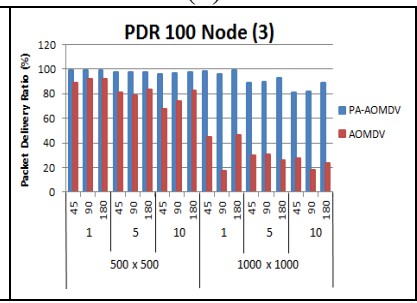

(f)
Gambar 9. Perbandingan nilai PDR pada 3 percobaan. (a) Node 50 percobaan 1; (b) Node 100 percobaan 1; (c) Node 50 percobaan 2; (d) Node 100 percobaan 2; (c) Node 50 percobaan 3; (d) Node 100 percobaan 3;

Pada Gambar 9 (a) dan Gambar 9 (b) yaitu hasil uji coba 1 , nilai optimum yang didapatkan dari hasil uji coba perbandingan PA-AOMDV dan AOMDV pada 50 node yaitu 99,482\% dan 86,034\%. Sedangkan nilai optimum yang didapatkan pada 100 node yaitu PAAOMDV 99,574\% dan AOMDV 91,632\%.

Pada Gambar 9 (c) dan Gambar 9 (d) yaitu hasil uji coba 2, nilai optimum yang didapatkan dari hasil uji coba perbandingan PA-AOMDV dan AOMDV pada 50 node yaitu $99,632 \%$ dan $91,296 \%$. Sedangkan nilai optimum yang didapatkan pada 100 node yaitu PAAOMDV 99,775\% dan AOMDV 95,116\%.

Pada Gambar 9 (e) dan Gambar 9 (f) yaitu hasil uji coba 3 , nilai optimum yang didapatkan dari hasil uji coba perbandingan PA-AOMDV dan AOMDV pada 50 node yaitu $99,567 \%$ dan $89,780 \%$. Sedangkan nilai optimum yang didapatkan pada 100 node yaitu PAAOMDV 99,354\% dan AOMDV 92,054\%.

Rata-rata hasil uji coba pada luas area $500 \times 500 \mathrm{~m}^{2}$ untuk 50 node pada PA-AOMDV adalah $97,79 \%$ dan $76,45 \%$ pada AOMDV. Sedangkan rata-rata hasil uji coba untuk 100 node pada PA-AOMDV adalah 97,94\% dan $82,43 \%$ pada AOMDV.

Rata-rata hasil uji coba pada luas area $1000 \times 1000$ $\mathrm{m}^{2}$ untuk 50 node pada PA-AOMDV adalah $90,37 \%$ dan 8,35\% pada AOMDV. Sedangkan rata-rata hasil uji coba untuk 100 node pada PA-AOMDV adalah $91,26 \%$ dan $30,39 \%$ pada AOMDV.

\subsection{Analisis Routing Overhead}

Skenario uji coba keempat atau yang terakhir pada penelitian ini adalah melakukan analisis terhadap routing overhead. Definisi routing overhead telah dijelaskan pada pembahasan sebelumnya.

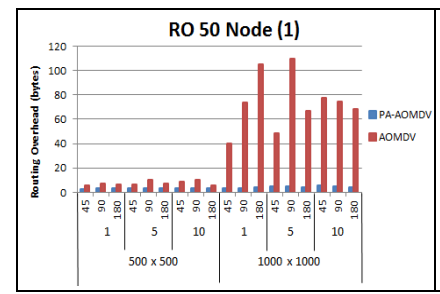

(a)

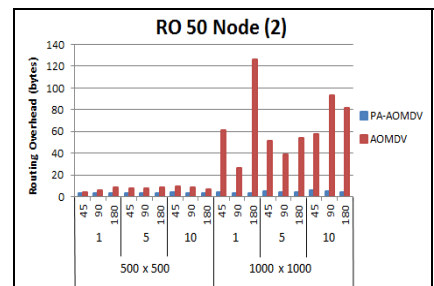

(c)

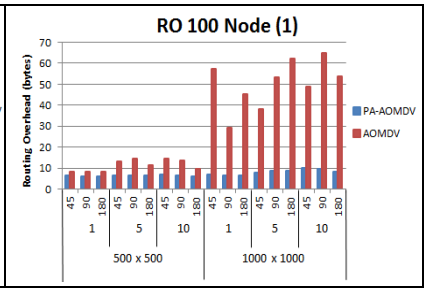

(b)

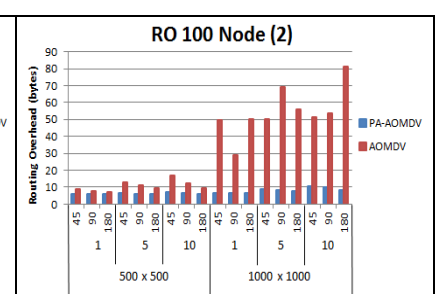

(d) 


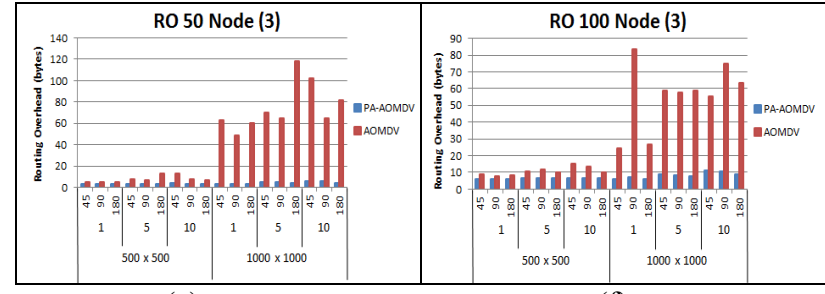

(e)

(f)

Gambar 10. Perbandingan nilai routing overhead pada 3 percobaan. (a) Node 50 percobaan 1; (b) Node 100 percobaan 1; (c) Node 50 percobaan 2; (d) Node 100 percobaan 2; (c) Node 50 percobaan 3; (d) Node 100 percobaan 3;

Pada Gambar 10 (a) dan Gambar 10 (b) yaitu hasil uji coba 1 , nilai optimum yang didapatkan dari hasil uji coba perbandingan PA-AOMDV dan AOMDV pada 50 node yaitu 2,957 dan 5,379. Sedangkan nilai optimum yang didapatkan pada 100 node yaitu PA-AOMDV 5,898 dan AOMDV 8,010. Pada Gambar 10 (c) dan Gambar 10 (d) yaitu hasil uji coba 2, nilai optimum yang didapatkan dari hasil uji coba perbandingan PAAOMDV dan AOMDV pada 50 node yaitu 2,922 dan 4,112 . Sedangkan nilai optimum yang didapatkan pada 100 node yaitu PA-AOMDV 5,753 dan AOMDV 7,004. Pada Gambar 10 (e) dan Gambar 10 (f) yaitu hasil uji coba 3, nilai optimum yang didapatkan dari hasil uji coba perbandingan PA-AOMDV dan AOMDV pada 50 node yaitu 2,911 dan 4,928. Sedangkan nilai optimum yang didapatkan pada 100 node yaitu PA-AOMDV 5,860 dan AOMDV 7,938. Rata-rata hasil uji coba pada luas area $500 \times 500 \mathrm{~m}^{2}$ untuk 50 node pada PA-AOMDV adalah 3,17 bytes dan 7,44 bytes pada AOMDV. Sedangkan rata-rata hasil uji coba untuk 100 node pada PA-AOMDV adalah 6,27 bytes dan 10,82 bytes pada AOMDV. Rata-rata hasil uji coba pada luas area $1000 \mathrm{x}$ $1000 \mathrm{~m}^{2}$ untuk 50 node pada PA-AOMDV adalah 4,30 bytes dan 71,37 bytes pada AOMDV. Sedangkan ratarata hasil uji coba untuk 100 node pada PA-AOMDV adalah 8,16 bytes dan 53,52 bytes pada AOMDV.

\section{Kesimpulan dan SARAN}

\subsection{Kesimpulan}

Setelah melakukan simulasi dan analisa terhadap kedua algoritma protokol routing PA-AOMDV dan AOMDV maka dapat diambil kesimpulan sebagai berikut :

a. Dari hasil analisis simulasi, efisiensi pencarian rute dengan menggunakan PA-SHORT meningkatkan kinerja dalam hal throughput. Hasil throughput pada PA-AOMDV mengalami peningkatan sebesar $16,04 \%$ untuk 50 node dan $11,55 \%$ untuk 100 node dengan luas area $500 \times 500 \mathrm{~m}^{2}$. Sedangkan pada luas area 1000 x $1000 \mathrm{~m}^{2}$, PA-AOMDV mengalami peningkatan sebesar $61,84 \%$ untuk 50 node dan 45,2\% untuk 100 node.

b. Hasil average end-to-end delay pada PAAOMDV mengalami penurunan sebesar 0,043\% untuk 50 node dan 0,038\% untuk 100 node dengan luas area $500 \times 500 \mathrm{~m}^{2}$. Sedangkan pada luas area $1000 \times 1000 \mathrm{~m}^{2}, \mathrm{PA}-$ AOMDV mengalami penurunan sebesar 0,066\% untuk 50 node dan 0,12\% untuk 100 node.

c. Hasil packet delivery ratio pada PA-AOMDV mengalami peningkatan sebesar $15,5 \%$ untuk 50 node dan $21,34 \%$ untuk 100 node dengan luas area $500 \times 500 \mathrm{~m}^{2}$. Sedangkan pada luas area $1000 \times 1000 \mathrm{~m}^{2}$, PA-AOMDV mengalami peningkatan sebesar $60,87 \%$ untuk 50 node dan $82,02 \%$ untuk 100 node.

d. Hasil routing overhead pada PA-AOMDV mengalami penurunan sebesar $4,27 \%$ untuk 50 node dan 4,55\% untuk 100 node dengan luas area $500 \times 500 \mathrm{~m}^{2}$. Sedangkan pada luas area $1000 \times 1000 \mathrm{~m}^{2}$, PA-AOMDV mengalami penurunan sebesar $67,07 \%$ untuk 50 node dan 45,36\% untuk 100 node.

e. Kinerja protokol AOMDV meningkat menggunakan algoritma Path Aware SHORT. PA-SHORT dapat digunakan untuk meningkatkan optimalisasi routing dengan memantau rute secara bertahap mengalihkan jalur setiap kali short-cut ditemukan.

f. Hasil simulasi menunjukkan protokol routing PA-AOMDV memiliki hasil throughput yang lebih tinggi, hasil average end-to-end delay yang lebih rendah, hasil PDR yang lebih tinggi, dan hasil routing overhead yang lebih rendah. Dari hasil tersebut dapat diambil kesimpulan bahwa PA-AOMDV mempunyai performa kerja yang lebih baik dari AOMDV standar tanpa modifikasi.

\subsection{Saran}

Berdasarkan kesimpulan di atas, maka peneliti dapat memberikan saran - saran sebagai berikut :

a. Melakukan penelitian menggunakan protokol routing yang lain pada jaringan MANET.

b. Mencoba menggunakan protokol routing sejenis dengan beberapa parameter simulasi 
yang berbeda dengan yang sudah dilakukan pada penelitian ini.

c. Melakukan penelitian menggunakan protokol routing yang sama dengan metode yang lain.

\section{DAFTAR PUSTAKA}

[1] Basagni, Conti, Giordano, and Stojmenovic, "Mobile Ad Hoc Networking With a View of 4G Wireless: Imperatives and Challenges," Mob. Ad Hoc Netw., 2004.

[2] H. Abdulwahid, B. Dai, B. Huang, and Z. Chen, "Scheduled-links multicast routing protocol in MANETs," J. Netw. Comput. Appl., vol. 63, pp. 56-67, 2016.

[3] M. K. Marina and S. R. Das, "On-demand multipath distance vector routing in ad hoc networks," Proc. Ninth Int. Conf. Netw. Protoc. ICNP 2001, pp. 14-23, 2002.

[4] A. Mehta and A. Gupta, "Retrospection and comparison of Dsdv and Aomdv routing protocols in Manet using Ns-2," Proc. 2014 Int. Conf. Issues Challenges Intell. Comput. Tech. ICICT 2014, pp. 325-329, 2014.

[5] M. K. Marina and S. R. Das, "Ad hoc on-demand multipath distance vector routing," Wirel. Commun. Mob. Comput., vol. 6, no. 7, pp. 969988, 2006.

[6] Kaur and Singh, "Scenario Based Analysis of Various Protocols in MANET," Int. J. Electron. Commun. Technol., vol. 6, no. 3, pp. 110-114, 2015.

[7] A. Nasipuri, R. Castañeda, and S. R. Das, "Performance of multipath routing for ondemand protocols in mobile Ad Hoc networks," Mob. Networks Appl., vol. 6, no. 4, pp. 339-349, 2001.

[8] N. Nurfiana, "Perbaikan Protokol Routing Ad Hoc on- Demand Multipath Distance Vector ( Aomdv ) Untuk Mendapatkan Rute Yang Stabil Menggunakan Link Expiration Time ( Let )," 2012.

[9] C. Gui and P. Mohapatra, "SHORT : Self-Healing and Optimizing Routing Techniques for Mobile Ad Hoc Networks," ACM Int. Symp. Mob. Ad Hoc Netw. Comput., pp. 279-290, 2003.

[10] Devulapally, "Performance Analysis Of Ad-Hoc on Demand Distance Vector and Ad-Hoc on Demand Multipath Distance Vector," Jawaharlal Nehru Technol. Univ. Andhra Pradesh, India, 2016.
[11] A. H. Jatmika, S. Djanali, and M. Husni, "Optimasi Routing Pada Jaringan MANET Menggunakan MEDSR dan LET," Semin. Nas. Manaj. Teknol. XIII. Progr. Stud. MMT-ITS, 2011.

[12] Nainggolan, Abdurohman, and Sudiharto, "Pengaruh Protokol AOMDV dan MP-OLSR Pada MANET Terhadap Penggunaan Aplikasi VolP," Tek. Inform. Fak. Tek. Inform. Univ. Telkom, 2012.

[13] Fauzi, Istikmal, and Mayasari, "Analisis Performansi Multipath Routing Pada Jaringan Mobile Adhoc," Pros. Semin. SSTI, pp. 29-32, 2016.

[14] R. Asokan, A. M. Natarajan, and C. Venkatesh, "Quality-of-Service Routing Using Path and Power Aware Techniques in Mobile Ad Hoc Networks," J. Comput. Syst. Networks, Commun., vol. 2008, pp. 1-7, 2008.

[15] N. Fahriani, S. Djanali, and A. M. Shiddiqi, "Efisiensi Rute Pada Protokol Dynamic Source Routing Menggunakan Path Aware-Short," Eksplora Inform., vol. 2, no. 1, pp. 37-48, 2012. 